Bol. Acad. peru. leng. 64. 2018 (47-71)

\title{
JOSÉ RUIZ ROSAS: EL BRILLO ESENCIAL DETRÁS DE LA OSCURIDAD PERFECTA ${ }^{(*)}$
}

\section{JOSÉ RUIZ ROSAS: THE ESSENTIAL BRIGHTNESS BEHIND THE PERFECT DARKNESS ${ }^{(*)}$}

\author{
Manuel Pantigoso \\ Academia Peruana de la Lengua
}

\section{Resumen:}

Luego del perfil biográfico, se destaca la presencia de José Ruiz Rosas dentro de la generación del 50 y las coincidencias de su lírica con el giro clásico y moderno de Carlos Germán Belli; y también con el trascendentalismo poético de César Atahualpa Rodríguez. Se estudian otros temas de su poética: la animación de los objetos, el candor irónico, la poeticidad y la entraña arequipeña y humanista, para culminar con las conclusiones sobre una poesía que permite acercarse al conocimiento esencial del ser humano.

\section{Abstract:}

After the biographical profile, we highlight the presence of José Ruiz Rosas within the Generation of ' 50 and the coincidences of his lyric with

(*) Conferencia del ciclo «En el nombre del Perú» leída en Radio Filarmonía, el 18 de noviembre de 2018.

Conference on the cycle «In the name of Peru» read on Radio Filarmonía, November 18, 2018. 
https://doi.org/10.46744/bapl.201802.003

the classic and modern turn of Carlos Germán Belli; and also with the poetic transcendentalism of César Atahualpa Rodríguez. Other themes of his poetics are studied: the animation of objects, the ironic candor, the poeticity and the humanist and Arequipa essence, culminating with conclusions about a poetry that allows to approach the essential knowledge of human beings.

Palabras clave: Arequipa, esencial, tradición, modernidad.

Key words: Arequipa, essential, tradition, modernity.

Fecha de recepción:

Fecha de aceptación:
$04 / 08 / 2018$

$31 / 10 / 2018$

\section{Introducción}

Este trabajo está dedicado a José Ruiz Rosas, poeta nacido en Lima (1928), pero con profundas raíces emocionales en Arequipa, tierra que siempre lo acogió como hijo ilustre y en la que, por amor a ella, se instalara durante casi 70 años, en 1949. Las nuevas promociones de vates conocieron muy poco a este lírida que llevó una carrera literaria con perfil bajo en cuanto a oropeles y publicidad. Sin embargo, fueron varios los estudiosos que destacaron su alta poesía y no escatimaron elogios para señalarlo como un poeta esencial, con gran densidad en su mensaje. Por ejemplo, él aparecerá en la importante Antología de la Poesía Peruana (1973) de Alberto Escobar, y en Poesía Peruana Siglo XX (1999) confeccionada por Ricardo González Vigil. Por su parte, Jorge Cornejo Polar, en su Estudio y Antología de la Poesía en Arequipa Siglo $X X$ (1990), lo situará entre las grandes figuras de la poesía mistiana. El 2009, con el apoyo del Gobierno Regional de Arequipa, se editó su obra poética que comprendía los textos fechados de 1949 al 2009. Hace poco apareció en España otro tomo que recopila toda su poesía 
https://doi.org/10.46744/bapl.201802.003

con el título de Inventario permanente (2018). Este libro es el reflejo de la admiración que le profesa la tierra española. Fallecido el 29 de agosto último, Ruiz Rosas nos dejó su palabra trascendente, el ritmo indesmayable de su fe y esa pasión de su entraña arequipeña.

\section{Itinerario vital}

Hemos señalado que el vate no nació en Arequipa, pero su deseo al regresar hace algunos años a Lima fue el de ser enterrado en el suelo de sus amores, en ese estrato emocional que sostuvo y maceró sus versos. $\mathrm{Y}$ su pedido fue cumplido: tuvo las exequias más arequipeñistas. Pero hagamos una breve síntesis de su vida. En 1946, a los 18 años, ingresó a la Facultad de Química de la Universidad de San Marcos y, al año siguiente, a la Escuela de Periodismo de la Universidad Católica. En 1949, a los 21 años, llegaría a Arequipa por requerir de un clima favorable para aliviar el asma que padecía desde niño. Al año siguiente viviría el levantamiento popular sucedido entre el 13 y el 17 de junio de 1950, en el cual la ciudad mistiana se puso de pie en contra de la dictadura de Odría. Durante esos días, el pueblo resistió tenazmente y destacó el coraje de los jóvenes alumnos del Colegio de la Independencia. Esta gesta sería cantada por otro brillante poeta, el cuzqueño Luis Nieto en su Romancero del pueblo en armas.

En la ciudad de Mariano Melgar, Ruiz Rosas produjo la mayor parte de su trabajo poético, formaría su hogar y echaría raíces culturales a través de una librería que fundó con su esposa Teresa, en 1958. Vallejianamente bautizada con el nombre de Trilce, el local fue también un centro de animación cultural de la ciudad que llegó a cobijar a los principales escritores de los años 60. Al igual que su querido y admirado César Atahualpa Rodríguez, fue también director de la Biblioteca Municipal de Arequipa, cargo del que se jubiló en 1991. Como el español Ramón del Valle-Inclán o el boliviano Tristán Marof, su barba espesa fue el rasgo fisonómico más visible de José Ruiz Rosas. Su figura no pudo desligarse de este elemento primordial que le dio a su personalidad presencia y majestad en los círculos literarios. Él mismo escribiría (2009: 34): 
https://doi.org/10.46744/bapl.201802.003

Todavía, la barba.

Como si no bastara la ansiedad

o el saludo total

de las ventanas y las altas estatuas;

como si fueran poco las banderas,

las incesables hormas, los botones

y el malecón que los suicidas aman.

Como si las palomas fueran almas, como si no hubiera

salarios y sonrisas y secretos

metidos a reír en el espejo.

Y todavía, la barba.

(«Todavía la barba»)

\section{La generación del 50}

José Ruiz Rosas fue un claro representante de la generación del 50, junto con Jorge Eduardo Eielson (1921), Javier Sologuren (1922), Sebastián Salazar Bondy (1924), Blanca Varela (1926), Pablo Guevara (1930), entre otros. Esta generación se desarrolló con el peso de dos acontecimientos históricos: universal uno; nacional el otro. La Segunda Guerra Mundial, entre 1939 y 1945, trajo el derrumbe de creencias y sistemas políticos e ideológicos, así como una gran crisis espiritual. De otro lado, la experiencia democrática de 1945 a 1948, con el gobierno de Bustamante y Rivero, que fue quebrada por el golpe de Estado del general Odría. Esta generación vivió, pues, una realidad social y política de la que difícilmente alguien pudo sustraerse. Aquella dictadura marcó el rumbo poético de toda una década. Un espléndido relato sobre estos años es el que ofrece Mario Vargas Llosa en Conversación en la Catedral (1969). Por esos años, el Existencialismo (conocimiento de la realidad sobre la experiencia inmediata de la propia existencia) era la corriente filosófica en boga dentro del círculo literario y artístico en general. 
A un grupo de vates de esta generación se les empezó a denominar «poetas puros», por el nivel de recursos expresivos que experimentaban sus poéticas en donde el virtuosismo formal denotaba la asimilación de la modernidad literaria, especialmente de las raíces simbolistas y surrealistas. Estos poetas tenían como mentores literarios a Emilio Adolfo Westphalen y Martín Adán. En sus obras había depuración y transparencia de la palabra poética y, también, gran conocimiento de la poesía española, especialmente de la generación del 27. Algunos peruanos de este sector se aproximaron a las formas líricas de Vicente Aleixandre, Pedro Salinas, Jorge Guillén, García Lorca, Rafael Alberti. Esta apertura formal —al servicio de una visión totalizadora de la existencia- descubrió que el rótulo de "poesía pura» era solo una equívoca percepción de la crítica, pues lo «puro» y lo «social» coexistían en la mayoría de los integrantes de la generación. Como bien apuntará González Vigil (1999: 499) refiriéndose a la poesía de Eielson:

Hubo una sintonía honda en el cuestionamiento de la palabra que pretende valer por sí misma y suplantar la realidad, complaciéndose en hacer trizas los adornos y las convenciones artísticas; también en el testimonio angustioso de la decadencia o muerte de los seculares patrones de la «cultura occidental», así como en la búsqueda del absoluto y la reivindicación del cuerpo como único recinto de la experiencia humana.

Estas palabras fácilmente se aplicarían a la poesía de José Ruiz Rosas que desde un inicio compartió la preocupación por la técnica sin desmedro de la función vital. Él fue uno de los primeros que resistió esas frías etiquetas de «poeta puro»y «poeta social». Él supo equilibrar un lenguaje «emocional» con soporte formal a la vez, estrategia propia de su generación que se manifestó con fuerza en Arequipa, sobre todo en la forma de asumir ese nuevo «aire» de poesía universal. Leamos lo que al respecto dijo el crítico mistiano Jorge Cornejo Polar (1976: 36):

Es evidente, por otra parte, que la poesía que se comienza a hacer a partir de 1950 denota en sus cultivadores una mayor dosis de preocupación 
https://doi.org/10.46744/bapl.201802.003

por las cuestiones técnicas, una más enérgica «voluntad de estilo», para emplear una frase que ha hecho fortuna. Ello puede ser consecuencia en cierto grado de la influencia que ejercen autores extranjeros especialmente (de los nacionales solo cabría mencionar la poderosa presencia de Vallejo que, muy visible aún en el grupo del 50, se atenúa hasta casi desaparecer en el del 60). Podrían citarse sin ánimo exhaustivo nombres como los de Rimbaud, Rilke, Eliot, Neruda, Brecht, y también una cierta reaparición de surrealismo. Pero quizás más importante que la presencia de nombres propios o de escuelas es la de un aire de poesía universal flotando en el ambiente poético de Arequipa. Las puertas se han abierto, pues, a influjos de todas partes del mundo. Pero el movimiento no es solo de recepción pasiva, sino que se trata conscientemente de incorporar al Perú (a Arequipa) en el movimiento general de la poesía en el mundo. Como afirma Alberto Escobar, estos poetas conciben «al Perú y su literatura como una pieza en la dimensión de Hispanoamérica y el mundo».

Al lado de Ruiz Rosas aparecieron en la escena literaria poetas y narradores nacidos en Arequipa y otros que, no siendo oriundos de ella, formarían parte de su proceso literario. Podemos señalar los siguientes: Gustavo Valcárcel (1921), Efraín Miranda Luján (1927), Pedro Roger Cateriano (1927), Edgardo Pérez Luna (1928), Jorge Bacacorzo (1928), José Gonzalo Morante (1929), Enrique Huaco (1930), Luis Yáñez (1931) Oswaldo Reynoso (1932), Rosa del Carpio (1933), entre otros.

De modo general, los vates arequipeños del cincuenta iniciaron, pues, el abandono progresivo de la temática local para adoptar una fisonomía más universal, extendiendo sus raíces por las honduras del ser a fin de expresar la lucha y los conflictos del hombre en su vida diaria. Como bien señalará el propio Jorge Cornejo Polar (1990: 28): «Hay sin duda una renuncia al color local pero no - y esto es importante subrayaruna renuncia a la condición arequipeña muy clara en el pensar, en el sentir y en el actuar de estos escritores aunque no figure explícitamente en sus textos». 
https://doi.org/10.46744/bapl.201802.003

\section{Poesía esencial de Ruiz Rosas y trascendentalismo poético de Atahualpa Rodríguez}

José Ruiz Rosas estuvo muy cerca de aquellos fundadores de la poesía contemporánea de Arequipa. Nos referimos a César Atahualpa Rodríguez, Guillermo Mercado, Alberto Hidalgo, Percy Gibson. De este grupo selecto, la poética esencial de Ruiz Rosas se habría de ligar más con la poesía trascendentalista de Atahualpa Rodríguez. Hay ciertas coincidencias que conectan la poesía de ambos. No se trata de una influencia directa del autor de La Torre de las Paradojas y de Sonatas en tono de silencio. Algunas opciones verbales de Rodríguez y de Ruiz Rosas nos hacen pensar, más bien, en un diálogo fructífero. Podemos citar, por ejemplo, dos ideas básicas referidas al primero que se extienden al segundo: «retirado a su mundo interior, apelando a sus pulsaciones y a sus íntimos tormentos, el poeta enciende más su capacidad reflexiva y crítica; así puede descubrir y ver las esencias de las cosas y erguirse con el vigor de su propia invención»; «el mecanismo típico de la poesía está en la lucha externa-interna que permite el surgimiento de cenestesias o sensaciones internas actuando dentro de una verdadera espiral introyectiva ${ }^{1}{ }$. En Atahualpa Rodríguez, estos recursos de sensibilización y de movimiento interior son muy evidentes. En el poema «Alumbramiento», de su libro Sonatas en tono de silencio (p. 55), encontramos los siguientes versos: «Se me adelgaza la vivencia», "Mi opaco cuerpo trasparece», «Me estoy llenando de silencio», «Me apunta un bello luminoso/ que en mi sensorio lo evidencio». Sobre José Ruiz Rosas podemos citar el siguiente soneto en donde prevalecen también las sensaciones (Cornejo 1976: 201):

La sensación me alumbra en la pupila de cúrvido halo en el nadir, la fresca voluptidad que luna llena ofrezca a laxitosa añoranza que hila.

1 Ver La espiral introyectiva en la poesía de César Atabualpa Rodríguez, de M. Pantigoso. 
https://doi.org/10.46744/bapl.201802.003

Noche constela su estelar favila y, salpicando coruscante yesca, claras pupilas de funambulesca risa que goza de mi agor pupila.

Noche no quiero si el pensar me oprime así la sensación mientras me alumbra y misma sangre lentamente exprime.

Noche prefiero que en negror columbra alas huidas de águila que gime verme como ella penetrar en umbra. $(« \mathrm{III} »)$

\section{La animación de las cosas}

Esta es otra característica que muestra a José Ruiz Rosas como un poeta dirigido a la esencia del ser. Mediante la reelaboración de los sentidos, las impresiones y las emociones, el poeta tiene la facultad de animar las cosas, de proporcionar vitalidad a los seres inanimados. Así encuentra poesía en la calle, en los paseos públicos, en la realidad cotidiana, en todas partes donde dirige la mirada con el propósito de reconocerse, de extraer de lo cotidiano ese aspecto ingenuo y poderosamente expresivo. Leamos dos poemas (2009: 35), el segundo con dejo vallejiano:

Hay un montón de cosas, los semáforos, los hongos, la mitad, los acuarios, el adentro de los humildes corazones, el resbalón, el horizonte, las grietas y todo aquello heroicamente ubicado para siempre.

Repito, hay un montón de cosas que se nos clavan lentamente. («Hay un montón de cosas») 
https://doi.org/10.46744/bapl.201802.003

Es decir, que las cosas no están otras, es decir, que las calles y las casas contienen siempre gente que se observa; es decir, que la gente continúa observándose para ver quién es este con vestido que pasa y qué les duele al poste y a las nubes; es decir, qué mañana, por más que anoche volví sobre mi vida, me venderán también otro periódico y una bufanda, y algo que no quiera. («Es decir, que las cosas no están otras», p. 34)

El poeta hilvana las cosas de la ciudad tiñendo sus pasos con la sabia subjetividad que es producto del equilibrio entre lo racional y la emoción de lo cotidiano. Razón tiene Jorge Nájar cuando señala (Ruiz 2009: 470):

En su poética no parece haber oposición entre lo público y lo privado porque en su universo todo es íntimo. Muchos de sus poemas traducen una aventura existencial que pasa por el autorretrato dentro del conjunto social para entornar el drama de la propia dignidad en el marco más amplio y que traduce la íntima relación del yo poético con la materialidad de lo cotidiano.

\section{El candor irónico como unión de lo clásico y lo moderno}

Un aspecto crucial en la obra de José Ruiz Rosas es el equilibrio entre tradición y modernidad. En ambos casos, su verso es fluido y concentrado a la vez. Su primera colección data de 1951: Sonetaje, un conjunto de sonetos que todavía estaban cuajando un estilo, al igual que sus textos de Invocada presencia (1952) y de Elegía (1955). Sería, sin embargo, con Esa noche vacía que el poeta se da de lleno en lo que sería su poética, transida de emoción y de retorcimiento que saben ir de lo cotidiano hacia lo trascendente a través de lo clásico y moderno, como bien ha de apuntar Alberto Escobar (1973: 179): «Salvo un libro inicial, su obra posterior revela un constante y severo trabajo que se escribe en la línea de la poesía 
especulativa, pero que a través del relieve de lo grotesco e inhumano consigue resolver su poética en una visión de candor irónico».

La tradición en la poesía de Ruiz Rosas no es, definitivamente, una experiencia pasiva. Tiene sin duda un punto de contacto $-\mathrm{o}$ de correlación-, en esa vivencia de lo clásico propia de Martín Adán y de Carlos Germán Belli, que no se inscribe en los paradigmas de «lo bello», «lo armonioso», «lo equilibrado». La impronta de ellos es fuerte, novedosa, intrigante, sorpresiva, desafiante. En Carlos Germán Belli hay, además, la configuración de un híbrido textual deliberado, de giros arcaicos y nuevos ${ }^{2}$. José Ruiz Rosas evoca, de esa manera, una materia clásica y moderna desde una perspectiva personal en donde el yo va, poco a poco, «cayendo en la modorra». Leamos este poema (2009: 232):

De aquí, de allá, los cuatro

—el 1, el 2, el 3, el 4-,

con igual persistencia te saludan,

te jalan, te rodean

por turno, equivalentes, incesantes,

en cartesianas rejas ubicándote

y cada uno, dos, tres, cuatro,

tiene a su vez sus cuatro vastos puntos cardinales

dándote cuerda para todos lados, alocando la brújula del tiempo, marchitando la rosa en aires raros de aquí, de allá, los cuatro, los mismos cuatro y sus constantes múltiplos como crueles tentáculos del orbe te azuzan, te electrizan y te palpan, con ventosas de tibios artificios

2 Ricardo González Vigil, refiriéndose a los vates de la generación del cincuenta, apunta que «siendo muy distintos entre sí cada uno, casi con un lenguaje, con un código personal, se caracterice a poetas con los cuales se puede ver algunos vínculos, como ocurre con José Ruiz Rosas y Carlos Germán Belli o Leopoldo Chariarse». En José Ruiz Rosas. Inventario permanente, 2018, p. 514. 
https://doi.org/10.46744/bapl.201802.003

hasta que vas cayendo en la modorra, vas hablando de ti contigo mismo como el centro abisal de un remolino enloquecido en nadas y despueses.

(«De aquí, de allá, los cuatro»)

Este poema forma parte de un conjunto de nueve textos reunidos bajo el nombre de «Epístola a los transeúntes». Con ellos, el poeta ofreció una exposición mural de carteles de poesía en la «Librería del Pasaje», Arequipa, en mayo de 1975. Fue un homenaje al estremecido mensaje vallejiano, de ahí que los poemas tengan esa cercanía con el discurso humanísimo del gran vate santiaguino (2018: 278).

Aquí mi descendencia

con resfríos;

aquí mi luz eléctrica,

mis libros;

aquí mi agua potable,

mis amigos,

mi vida numerada y preservada

de peligros;

aquí mi canto, alegre o triste, andando

sus caminos;

aquí como una sombra deslizándose

lo que vivo;

en hipérbole haciendo sus donaires

lo más mínimo;

aquí con los augures entre víctima

y asesino;

aquí, al fin y al cabo, con mis cosas

tan tranquilo

y allá cuánta desgracia palpitando,

genocidio,

cuánto dolor atroz para los hombres

aguerridos, 
cuánta vergüenza al mundo por los siglos

de los siglos.

$$
\text { («Aquí mi descendencia») }
$$

Siguiendo la línea del autor de Poemas Humanos, José Ruiz Rosas (2018: 279) dejará constancia de su profunda vena poética. Sus versos transmitirán una alta tensión en donde vida y muerte conviven y se enraízan en el hondo ser:
Ardes, vida, si dueles, si pareces un esmeril intruso entre ojo y párpado, aquí pensando al sol este cadáver en su muerte, sin luto y prematura, aquí con estas diarias ondas múltiples cargadas de cuchillos y de plomo para desayunar muy satisfechos; aquí presto al rezo y la blasfemia, encerrados en cadas y en cascadas abiertos hacia adentro, como truenos, $\tan$ fenecidos, $\tan$ felices, $\tan$ hechos a la medida de las urnas. («Ardes, vida, si dueles, si pareces»)

Ricardo González Vigil agrega el rango grotesco-experimental en la certera opinión (1999, t. 1: 668):

Su apego a las formas tradicionales, en sus manos sometidas a una combustión desarticulada (al modo de lo que Mariátegui, refiriéndose a Martín Adán, calificó de «antisonetos», de sonetos que dejan de serlo, que estallan ante una energía innovadora inocultable (...) Nótese la afinidad que esa formulación de lo tradicional posee con la obra de Belli, aunque en el caso de Ruiz Rosas actúe el legado grotesco-experimental de los poetas arequipeños César A. Rodríguez, Percy Gibson y Alberto Guillén, tradición local a la que se suma el magisterio de Martín Adán. 
https://doi.org/10.46744/bapl.201802.003

En sus siguientes libros (Urbe, Ciego de ver y Cuenca Matinal, los tres de 1968), el poeta enrumba hacia la plena madurez, hacia una palabra de claroscuros y oposiciones en donde el amor empieza a ser el tema primordial. Ejemplifiquemos con el texto «Barco de olas encendidas» (2009: 73):

Barco de olas encendidas

en ella misma flota la llaga del amor, instrumento de luz, exacta cavidad del tacto, las alturas de fuego adonde arribo, gemas vivas, rotundas yemas de la sangre, oh desiderante de abandonadas fuerzas, dulce línea en torno de la invisible plenitud separando el universo y los arcanos próximos del gozo, sumergidas palabras por las raíces de la piel para el cabal susurro, la queja feliz de lo que vive, el viaje de lo más remoto, penetradas y dueñas de su aliento.

En Obra Poética (1949-2009), publicada por el Gobierno Regional de Arequipa, José Ruiz Rosas incluye libros en donde se amalgaman las formas tradicionales con los testimonios líricos de gran calado moderno. En ambas líneas, generalmente entrecruzadas, el poeta se siente como «pez en el agua». Por el lado en donde la tradición predomina encontramos Sonetaje (1949), Dizires Rimados (1969), Taller de poesía (1970), Sonetos conyugales (1971), Dobles (1971), Arakné (1972), Diálogo a solas (1982), Vecino de la muerte (1985) Llaki Urpi (1986). De otro lado, en la línea más experimental, encontramos Esa noche vacía (1956-1967), Cuenca matinal (1968), Urbe (1968), Inventario permanente (1970), Glosas (1970), Crónicas del Mol (1970), Cinema de los párpados adentro (1971), La prosa presa de prisa (1974), La sola palabra, (1976), Vigilia del cristal y de la bruma (1978), Tienda de ultramarinos (1978), Elogio de la danza (1980), Taller de poesía (1970), La primera sílaba (2000), Coge tus pies (2005-2009).

\section{Inventario permanente}

En Inventario permanente (2018), que amplía la valiosa y definitiva producción de José Ruiz Rosas, aparecen otros títulos además de los 
ya señalados: Sorda sombra (1968), Epístola a los transeúntes (1975), Viajes (1982), Variaciones ungaréticas (1999), El juego (2000), Estratos (2008-2009).

De estos poemarios quisiéramos referirnos a Dizires rimados, un conjunto de once escritos notables en donde el autor retorna al origen y a la formación de nuestro idioma. No se trata de insertarse en el más puro tradicionalismo conservador. Hay, más bien, una estrategia creativa, libertaria y abarcadora, frente a la cual José Ruiz Rosas señala en la introducción (2009: 83): «Los textos parecen pertenecer a un bardo de fines del siglo XIV, si bien el léxico y la ortografía empleados se remontan unas veces a siglos anteriores y, otras, se adelantan en la construcción de giros vocabulares, cosa muy común antes de las reglamentaciones de Nebrija».

La organización creativa del poeta se traza dentro de un espacio en donde la atmósfera está ahíta de lejanía y modernidad ética y moral donde parece que nada ha cambiado dentro de la dualidad origen-destino. Múltiple en el tiempo, la estrategia puede ser muy contemporánea e irse, también, hasta la formación del idioma español, como se aprecia en los siguientes versos:

Tamién andan agora en lides e matanças.

Los braços de los omnes atán son commo lanças.

Las vibdas e sos críos non recabdan pitanças.

Los reis de la Tirra por prez tien malandanças.

Mios ojos oi los vide los probes han dolor.

Sos carnes son siccina que claman a horror.

Trabaxan por tan sólo medrar el mal senyor.

Non tenien alegría; más viven con temor.

Varón saje et forte se llena de crueldat.

Mayor es la fazienda, non muda la maldat.

Miafé que oi lo digo por grande antigüidat.

Ser han tiempos eguales los de otra nova edat.

(«Crónica de ver», p. 87) 
Un texto concentrado y depurado en su lenguaje es Glosas. El conceptualismo no es de etiqueta, frío y banal; por el contrario, involucra al hombre en su sentido más hondo, en aquel que roza las contradicciones, las oscuridades y sus luces:

No solo por la víctima la compasión se mueve; la figura del otro nos confunde y aterra pensar solo en el círculo que eternamente encierra la conciencia de muerte como un altorrelieve ${ }^{3}$.

Un amigo es la piel, otro la soledad, otro el ensayo nocturno de la muerte.

Un amigo es también aquello abstracto.

Por eso a los amigos $\tan$ hermosos y raros hay que guardarlos siempre sin herirlos ${ }^{4}$.

La obra La prosa presa de prisa conjuga prosa y poesía. Es un libro sabroso que se adelantó en el Perú a lo que después se denominaría «microrrelatos». El humor de vanguardia y el toque existencialista se alían para darnos una versión más intensa y surrealista de la vida (2018: 262):

Con el objeto de perfeccionarse mutuamente se fundó un club de enemigos y todo marchó perfectamente, durante varios años, porque las asambleas eran tan pleitistas, las votaciones tan falsas y las ponencias tan astutas que los asociados frotábanse las manos de satisfecha envidia cada vez con mayor frecuencia.

$(« \mathrm{El}$ intruso»)

3 José Ruiz Rosas (2018: 208).

4 Ob. cit.:209. 
https://doi.org/10.46744/bapl.201802.003

Cuando por fin tuve la certeza de haberme despertado me di cuenta de que continuaba durmiendo y traté de decidir si debía volver a intentar despertarme o sumirme en las ensoñaciones.

(«Corpóreo», p. 264)

Elogio de la danza es, acaso, uno de los libros más intensos de Ruiz Rosas con el que obtuvo, en 1980, el Premio Internacional del Taller Coreográfico de la Universidad Autónoma de México, UNAM. González Vigil (1999, t. 1: 668) señala que con este poemario «Alcanzan una cima verdaderamente magistral sus dotes creadoras, labrando uno de los mejores poemas de sostenido aliento de la Generación del 50». En el poema es evidente la perfección formal, las imágenes dúctiles y concentradas, y ese plástico movimiento del universo imaginativo. Leamos solo un fragmento en donde está presente la «sumisa/ adhesión a la tierra/ por el ritmo y la forma que enlazadas/ hacen del cuerpo un universo inédito» (2009: 303):

Pero el cuerpo comprendía

la suma del corpúsculo a la mole del cerebro a la mínima molécula de la ameba al espíritu del caos a la perfecta escala de valores del sonido acordado fiel del todo al ruido universal de urbes y campos al mecánico estrépito en las fábricas y al silencio no solo de la muerte de la pleamar de la conciencia incluso del átomo gigante de hidrógeno suspenso en el espacio y es ya piramidal ya luz flexible ya cristal en la roca así erizado ya estalactita rígida ya elástico eslabón en fatídicas cadenas ya concreción del justiciero triunfo ya medida del tiempo ya inconclusa batalla de lo orgánico en el orbe 
https://doi.org/10.46744/bapl.201802.003

ya pieza del conjunto ya sumisa

adhesión a la tierra

por el ritmo y la forma que enlazadas

hacen del cuerpo un universo inédito

brinda su afán un mago

arquitecto de ensueños

que a la expresiva libertad señala

rumbos de luz metáforas de anhelo.

(«Elogio de la danza»)

\section{Un lenguaje de artes poéticas}

El virtuosismo formal de los "poetas del cincuenta» permitió que sus hallazgos se manifestaran a través de la palabra experimentada como palabra, es decir, a través de lo que se denomina «poeticidad». Al leer los textos de José Ruiz Rosas tenemos la sensación de que, desde el fondo, renacen concentradas diversas artes poéticas. Esto es así porque, a fin de cuentas, el vate se está refiriendo siempre, directa o indirectamente, a la propia poesía. Advirtamos, inclusive, que dos de sus libros llevan el nombre de Taller de Poesía y Taller de Poesía II. El poeta, como una necesidad vital, apremiante, le habla al poema de tú a tú: «tengo que estar en ti, ser parte tuya»; «sabes, tengo/ que inventar otro mundo si te ausentas» (2009: 397):

Tú que estuviste siempre en mis rodillas riéndote de mí, tú, Poesía venida en nubes de remotas islas a un naufragio flotando entre las brisas, tal el olor sensual con que agonizan en sus tallos las reinas coloridas; tengo que estar en ti, ser parte tuya cual imán en el frío, inmóvil hierro; ser tu sombra en las noches más oscuras caminar en tus pies al infinito, enamorarme sin saber de ti sino tu amor constante a lo impalpable, 
https://doi.org/10.46744/bapl.201802.003

tu estar aquí conmigo y los demás, tu ser yo en el plural más extranjero, en ti y en mí sin tiempo; sabes, tengo que inventar otro mundo si te ausentas.

(«Tú que estuviste siempre en mis rodillas»)

En Variaciones Ungaréticas — siguiendo la poética del futurismo hermético del italiano Ungaretti y de la humilde síntesis del haiku japonés-, sentará las bases de una estética y una ética a favor de lo humano y de lo sencillo. Leamos algunos textos (2018: 453):

En la cabeza

hueca

resuena

una insondable espera.

$* * *$

Arcángel de la muerte no te acerques espérame.

$* * *$

Calma, pasajero

cada día llegamos

a tiempo

$* * *$

Ah la palabra humilde con que se dicen

las cosas más difíciles.

$* * *$

Pintaría los dormitorios 
https://doi.org/10.46744/bapl.201802.003

del color

de los vientos.

En «Así escribo el poema. Doy un paso», siguiendo las huellas de su admirado César Atahualpa Rodríguez, Ruiz Rosas muestra el proceso introyectivo de un lenguaje que se nutre de la savia de sus emociones, de sus instintos a flor de vena y de sangre. Es un texto de altísimo nivel que fue leído como parte de su agradecimiento por la incorporación a la Academia Peruana de la Lengua, el 7 de julio de 2008. Previo al poema, diría sobre su pasión poética (2018: 253):

Sumergido hasta el extravío en el referido torrente, desde que tengo 12 años vengo intentando dar expresión escrita a mis sentimientos mediante el ejercicio de la poesía. La lengua y sus diversas artes, con la poesía como médula, permiten el milagro de acercarse al ser humano. Me he pasado la vida en ello y por tanto la poesía me ha socorrido siempre. Quiero por ello cerrar estas palabras que son solo de agradecimiento con unos versos del año 1974.

Así escribo el poema. Doy un paso, duermo, sonrío, lloro en mis adentros, mastico la ancha hiel de los instintos puestos a galopar, protones lúdicos flotando sus latentes emociones; miro la luz, que es el mirar más último antes de penetrar en cada arcano; oigo no sé qué cosas en los cantos de las aves por un momento libres y se me empuña el corazón sabiendo su final de cautivas o de víctimas; aspiro el aire altísimo que baja a decorar de oxígeno mis huesos; llego, me voy, distante en todo tiempo de la meta final que no he fijado; pulso la hora intacta que alumbrara el otoño de un ramo, atrapo el claro 
https://doi.org/10.46744/bapl.201802.003

destello de unos ojos fraternales, miro los flujos que soporta el mundo por pasos con sus callos melancólicos, torno, vuelvo a mirar y abro los ojos como un insomne búho en medio día y fijo las pupilas como el gato que pretendiera caza de aeroplanos, subo la cuesta, bajo, y subo, y bajo y conservo el imán del pavimento; llego, con mi codicia a manos llenas a regalarle el sol a todo el mundo y la sombra, la luna, los luceros como si todo yo fuera raíces, hojas y savia para estar callado como un laboratorio del abrazo. Así escribo el poema. Doy un paso.

\section{Arequipa en el verso de José Ruiz Rosas}

Son varios los testimonios y crónicas donde aparece el poeta mimetizado con la vida cultural arequipeña. Fue amigo leal de los bardos sobrevivientes de la vanguardia (Atahualpa Rodríguez, Guillermo Mercado, Alberto Hidalgo). También lo fue de los más jóvenes, a quienes estimuló permanentemente:

Su figura fue clásica durante décadas por las viejas calles del centro de Arequipa. Un terno y una frondosa barba dibujaban su paso.

Por las noches semejaba un símbolo viviente en foros y auditorios. Todos sabían que no era uno más. Murmuraban: es el poeta. El personaje cuya presencia daba relieve a la actividad cultural.

No necesitaba títulos ni currículo para ser alguien. Su nombre bastaba y era conocido: José Ruiz Rosas. Pero en una no frecuente fusión de respeto y cariño, para su extenso entorno de conocidos solo fue «don Pepe». $[\ldots]$

Estaba encantado de Arequipa. «La ciudad más cerca de Dios» diría más tarde de ella. La admiró por monumental en su 
arquitectura y su historia. Pueblo gravitante en el Perú, con marcada identidad y jerarquía cultural. Una nación dentro de otra nación y paisajistamente una acuarela, nos lo dijo. La hizo suya, se «nacionalizó»s.

Un poeta tan íntimamente ligado a todos los rincones de la Ciudad Blanca no podía dejar de cantar su azarosa y épica existencia. No necesitó ser tan explícito para encerrar en su verso el prodigioso vergel de los paisajes arequipeños. Así, la geografía mistiana aparecerá de forma decantada y sugerida; pero será en el volumen Taller de poesía II donde el vate dedicará tres estupendos poemas, en versos endecasílabos, a su querida Arequipa. El primero, en homenaje a Mariano Melgar, tiene el tono de la elegía. El poetahéroe es representado en noche silenciosa como una cristalina y romántica corriente de aire y sed. El segundo está ofrecido al íntimo Monasterio de Santa Catalina; y el tercero al sillar, elemento distintivo de la Ciudad Blanca. De este último son estos fragmentos (2009: 407):

Láctico río hasta la nieve ardido, harina de un metálico cereal, calcinada ceniza de las rocas, triturada osamenta del cristal $[\ldots]$ hospicio de la luz entre los limbos como un huésped total en claridad, albúmina del cuarzo derretido, mensajero abrumado de la espuma, alegoría quieta del relámpago, hibernada semilla del volcán. («Letanía del sillar»)

5 Internet: Bernardino Rodríguez. «La vida y trayectoria del poeta José Ruiz Rosas. En diario Correo: https://diariocorreo.pe/edicion/arequipa/la-vida-y-trayectoria-del-poetajose-ruiz-rosas $839035 / 5$ de noviembre de 2018, 17 horas. 
Leamos, para concluir, el siguiente soneto cuyo referente es sin duda Arequipa, aunque en él no aparezca su nombre. Está construido a base de la acumulación de epítetos para caracterizar la imagen trascendente de múltiples destellos (Cornejo, 1976: 211):

¡Jardín; corola; ardiente calabozo; innominable gruta; labio mudo; puerta del bien; hogar; rendido escudo; paladar apetente; antro del gozo!

iRemolino de miel; eterno pozo; perfecta realidad de lo desnudo; capilla personal; resuelto nudo; túnel del alma; imán; metal undoso!

iPuente del bosque a la región de ensueño; indulto del dolor; viva candela; frutecer de mandrágora y beleño!

iNido; país nocturno; ebria estela; abismo tentador; volcán sedeño; antípoda ideal; barco de vela! $(« \mathrm{XII})$

\section{Conclusiones}

1. José Ruiz Rosas pertenece a esa noble casta de poetas arequipeños que han quedado como arquetipos de la identidad nativa, aunque sin dejar de lado la mirada universal. La autoctonía en ellos no está en la mera descripción del ambiente y de la geografía, sino en la interiorización del mundo, tal como sucede con todo espíritu creador que sabe reaccionar frente a su propia historia.

- La poesía esencial de Ruiz Rosas significó despojarse de las vestiduras ornamentales para que la idea se expresase mediante un lenguaje ceñido y sugerente. Él supo que el arte esencial es enemigo absoluto 
del maquillaje, y que el sentimentalismo sucede en la superficie: es lo más fácil de hacer y de reproducirse.

- Su poesía no se comprende solo por las vías lógicas. Ella no es un refrán ni menos un silogismo. Para ingresar al brillo esencial de la palabra tuvo que oscurecer los sentidos. Dejó que los nervios se conectasen con el psiquismo aventurero para penetrar en la trascendencia.

- La manera de metaforizar de Ruiz Rosas se sostiene básicamente por la sorpresa: lo que tenemos delante lo percibimos de pronto mediante esa perspectiva asociativa capaz de aprehender lo poderosamente expresivo proveniente de lo cotidiano o de lo ingenuo.

2. El registro lírico y temático en José Ruiz Rosas pertenece al orden de lo insular. Severo y hermético en su forma y ascendencia conceptual; ese registro está, sin embargo, conectado de manera natural con la realidad, con todo lo que acontece en su ciudad y en el mundo. Oswaldo Chanove (Ruiz 2009: 476) dirá lo siguiente:

En la obra de José Ruiz Rosas llama la atención su peculiar manera de focalizar los temas, su actitud supuestamente un poco al margen del mundanal chirrido de lo contemporáneo, pero en realidad, al repasar lo vasto de su obra, resulta visible un frecuente registro de los temas de su tiempo. No dejándose tentar por aspavientos, sus poemas, admirablemente diseñados, jamás se animan a la violencia de juicios provocadores o imágenes chocantes.

3. Su obra publicada en el 2009 por el Gobierno Regional de Arequipa da cuenta de 28 poemarios. Este número se amplía a 35 en la edición del 2018 (Edit. española Huerga y Fierro). Fue pues, Ruiz Rosas, un poeta a tiempo completo, «a vena abierta». Estuvo en comunicación permanente con sus lectores, que fueron creciendo en número con los años.

4. «Versos cuajados en el fondo de la mente» es una acertada calificación de Carlos Germán Belli, quien le dedicará a su amigo el poema «Fe de oyente y de lector». El autor de Ob Hada Cibernética remata 
https://doi.org/10.46744/bapl.201802.003

con exactitud lírica su concepto sobre la poética de José Ruiz Rosas (2009: 467):

Y helo allí codo a codo con dos cumbres

del parnaso de América Española, leyendo en alta voz los versos suyos

cuajados en el fondo de la mente, sin duda alguna él grande como ambos; que aunque ha pasado largamente el tiempo, de tal hecho fe doy ahora en este nuevo siglo humano, y heme aquí oyente fiel tan complacido ayer como hoy por siempre.

Pero por igual el recuerdo vivo de sus versos al ras de cada página allí asaz como exacto pan llevar para la gula del lector voraz, y todo viene como anillo al dedo, pues de él es enjundiosa la palabra o medida o libérrima, que de su pluma brota como un río, en justa coincidencia con el espíritu o físico hombre.

Esta doble aseveración cuán fácil, porque quien es leído y es oído, tanto uno cuanto lo otro bien lo hace, por la razón de que en su propia grey pluma y pincel descuellan sobre todo, en el día por día de la vida, y decir esto en suma no es como el cristal quebradiza loa, mas firme verdad pura de la que también doy ahora fe. 


\section{BIBLIOGRAFÍA}

CORNEJO POLAR, J. (1976). Antología de la Poesía en Arequipa en el siglo XX. Arequipa, Instituto Nacional de Cultura Filial Arequipa.

. (1990). La poesía en Arequipa en el siglo XX. Lima, CONCYTEC y UNSA.

ESCOBAR, A. (1973). Antología de la Poesía Peruana, Lima, Peisa.

GONZÁLEZ VIGIL, R. (1999). Poesía Peruana Siglo XX, Tomo I, Lima, Ediciones Copé.

PANTIGOSO, M. (1970). La espiral introyectiva en la poesía de César Atabualpa Rodríguez. Lima, UNMSM.

RUIZ ROSAS, J. (2009). Obra poética (1949-2009). Arequipa, Gobierno Regional de Arequipa.

. (2018). Inventario permanente. Poesía esencial. Madrid: Huerga y Fierro. 